\section{0-015 LONG-TERM CLINICAL AND ANGIOGRAPHIC OUTCOMES IN 140 PATIENTS WITH 166 CEREBRAL ANEURYSMS TREATED WITH THE PIPELINE EMBOLIZATION DEVICE: A MULTI-CENTER COHORT STUDY}

1J Delgado Almandoz, ${ }^{2} \mathrm{O}$ Tenreiro-Picon, ${ }^{1} \mathrm{Y}$ Kayan, ${ }^{1} \mathrm{~J}$ Fease, ${ }^{1} \mathrm{~J}$ Scholz, ${ }^{1} \mathrm{~A}$ Milner, ${ }^{3} \mathrm{M}$ Mulder, ${ }^{2} \mathrm{~A}$ Tenreiro. 'Neurointerventional Radiology, Abbott Northwestern Hospital, Minneapolis, MN; ${ }^{2}$ Neurointerventional Radiology, Clinica El Avila, Caracas, Venezuela, Bolivarian Republic of Venezuela; ${ }^{3}$ Critical Care Medicine, Abbott Northwestern Hospital, Minneapolis, MN

\subsection{6/neurintsurg-2016-012589.15}

Purpose To examine long-term clinical and angiographic outcomes in a consecutive cohort of patients with cerebral aneurysms treated with the Pipeline Embolization Device (PED) in 2 referral centers.

Materials and methods We conducted a retrospective review of all patients with cerebral aneurysms treated with the PED at 2 referral medical centers between March 10th, 2011 and November 5th, 2015. Baseline patient and aneurysm characteristics, intra-operative, peri-operative and delayed complications were recorded. Aneurysm volumes in initial and follow-up angiographic studies were calculated using AngioCalc. Clinical outcomes were categorized using the modified Rankin Scale (mRS).

Results 140 patients underwent 150 PED procedures to treat 166 cerebral aneurysms during the study period. 109 patients were women (78\%) and 31 men (22\%). Mean age was 55 years (range 15-81 years). 87 aneurysms were incidental (52\%), 39 recurrent (24\%), 23 symptomatic (14\%) and 17 ruptured (10\%, 11 treated sub-acutely and 6 treated acutely). 22 aneurysms were fusiform (13\%), 7 dissecting (4\%) and 6 blister (4\%). 125 aneurysms were located in the internal carotid $(75 \%), 15$ in the middle cerebral $(9 \%), 10$ in the anterior cerebral (6\%), 10 in the vertebral (6\%), 4 in the basilar (2\%) and 2 in the posterior cerebral arteries (1\%). Mean aneurysm size was $10.2 \mathrm{~mm}$, mean neck was $6.4 \mathrm{~mm}$, mean dome-toneck ratio was 1.6. Mean number of PEDs deployed per aneurysm was 1.1. Adjunctive coiling was performed in 15 aneurysms (9\%). The table summarizes the intra-operative, peri-operative and delayed complications, categorized by the first 75 and subsequent 75 PED procedures. There was a statistically-significant decrease in the rate of any intra-operative as well as disabling treatment-related complications between the first 75 and next 75 PED procedures. Similarly, there was a trend toward a decrease in treatment-related mortality between the first 75 and the next 75 PED procedures. Angiographic follow-up was obtained in 139 aneurysms (84\%), with a mean time to last angiographic follow-up of 18.1 months. At last follow-up, 109 aneurysms were completely occluded (78.4\%), 10 had near-complete occlusion ( $\geq 90 \%$ volume reduction, $7.2 \%$ ), and 20 aneurysms had $<90 \%$ volume reduction (14.4\%, mean volume reduction 53\%). 4 aneurysms were retreated (2.9\%). Among the 16 aneurysms symptomatic from mass effect $(10 \%)$, symptoms completely resolved in 8 patients (50\%), improved in 3 patients (19\%), remained unchanged in 3 patients (19\%) and worsened in 2 patients (12\%). There were 3 post-operative aneurysm ruptures $(1.8 \%), 2$ of which occurred in ruptured aneurysms treated acutely with the PED.

Conclusions The PED is an effective treatment for wide-neck cerebral aneurysms, with high long-term complete/near-complete aneurysm occlusion rates and low retreatment rates. The risk of intra-operative and disabling treatment-related complications decreases significantly with increased experience in PED use and patient management.

Abstract 0-015 Table 1 Complications in cerebral aneurysms treated with pipeline

\begin{tabular}{lllll}
\hline & $\begin{array}{l}\text { All 150 } \\
\text { procedures } \\
(\%)\end{array}$ & $\begin{array}{l}\text { First 75 } \\
\text { procedures } \\
(\%)\end{array}$ & $\begin{array}{l}\text { Next 75 } \\
\text { procedures } \\
(\%)\end{array}$ & $\begin{array}{l}\text { p- } \\
\text { value* }\end{array}$ \\
\hline Any Intra-Operative Complication & $12(8)$ & $10(13.3)$ & $2(2.7)$ & 0.016 \\
Resulting in mRS > 2 & $1(0.7)$ & $1(1.3)$ & 0 & 1 \\
Any Peri-Operative Complication: & $27(18)$ & $12(16)$ & $15(20)$ & 0.67 \\
Resulting in mRS $>2$ & $8(5.3)$ & $6(8)$ & $2(2.7)$ & 0.28 \\
$\begin{array}{l}\text { Any Delayed Complication: } \\
\text { Resulting in mRS > 2 }\end{array}$ & $6(4)$ & $4(5.3)$ & $2(2.7)$ & 0.68 \\
$\begin{array}{l}\text { Any Treatment-Related } \\
\text { Complication Resulting in }\end{array}$ & $1(0.7)$ & $1(1.3)$ & 0 & 1 \\
mRS > 2 & $10(6.7)$ & $8(10.7)$ & $2(2.7)$ & 0.049 \\
Treatment-Related Mortality & $5(3.6)$ & $4(5.9)$ & $1(1.4)$ & 0.19 \\
\hline
\end{tabular}

${ }^{*} p$-value for the difference between the first 75 and next 75 procedures using Fisher's exact test. mRS: Modified Rankin Scale. Peri-operative complication: occurring up to postoperative day 30. Delayed complication: occurring after post-operative day 30.

Disclosures J. Delgado Almandoz: 2; C; MedTronic Neurovascular. O. Tenreiro-Picon: None. Y. Kayan: 2; C; MedTronic Neurovascular. J. Fease: None. J. Scholz: None. A. Milner: None. M. Mulder: None. A. Tenreiro: None.

\section{0-016 IN SITU TISSUE ENGINEERING: ENDOTHELIAL GROWTH PATTERNS AS A FUNCTION OF FLOW DIVERTER DESIGN}

${ }^{1} \mathrm{M}$ Marosfoi, ${ }^{1} \mathrm{E}$ Langan, ${ }^{2} \mathrm{~L}$ Strittmatter, ${ }^{1} \mathrm{~K}$ van der Marel, ${ }^{3} \mathrm{~J}$ Arends, ${ }^{4} \mathrm{~S}$ Loganathan, ${ }^{2} \mathrm{G}$ Hendricks, ${ }^{1} \mathrm{~A}$ Puri, ${ }^{1} \mathrm{~A}$ Wakhloo, ${ }^{1} \mathrm{M}$ Gounis. 'Radiology, University of Massachusetts, Worcester, MA; ${ }^{2}$ Cell Biology, University of Massachusetts, Worcester, MA; ${ }^{3}$ Preclinical Research, Stryker Neurovascular, Fremont, CA; ${ }^{4}$ Research and Development, Stryker Neurovascular, Fremont, CA

\subsection{6/neurintsurg-2016-012589.16}

Purpose To identify progenitor cells involved in flow diverter (FD) endothelialization and to assess the impact of FD design on aneurysm occlusion and endothelialization patterns.

Materials and methods Sixteen complex, elastase induced aneurysms in white New Zealand rabbits were randomly treated with 2 different types of single-layer braided flow diverters made of cobalt-chrome alloys: Device-1 - 48 wires

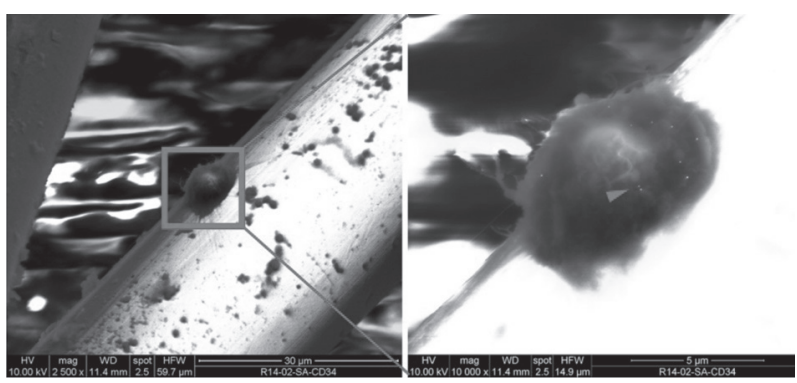

Abstract 0-016 Figure 1 Representative immunogold SEM results showing an endothelial progenitor cell attached to a wire of device-1 at 10 days from implant (left). High magnification image confirms gold staining of CD34 (arrowhead, right) 